\title{
Transient Modeling of Induction Motors considering Space Harmonics
}

\author{
L. Di Leonardo, M. Popescu, M. Tursini, F. Parasiliti, M. Carbonieri
}

\begin{abstract}
This paper presents a transient mathematical model for induction motors based on space harmonics and its validation by finite-elements method comparison.

The model is based on the computation of the magnetomotive force-wave for squirrel cage induction motors, and accounts for the geometry and physical dimensions of the stator and rotor windings. The harmonic components of the airgap field are calculated at each time-step considering the currents in the stator windings and in the rotor bars, the latter modeled as overlap of contiguous coils, as well as the rotor position. The proposed model is compared with finite elements calculations to outline differences and effects of simplifications and harmonic order.
\end{abstract}

A $200 \mathrm{~kW}$ induction motor designed for a premium electric vehicle is assumed as case-study.

Index Terms-- Induction motors, Electromagnetic model, Finite element analysis, Cage rotors, Motor simulation

\section{NOMENCLATURE}

a $\quad$ complex conjugate of $a$;

$i_{r k} \quad$ current in the $k$-th bar of the rotor cage;

$e_{r k} \quad$ e.m.f. induced in the $k$-th bar of the rotor cage;

$i_{s h} \quad$ current in the $h$-th stator phase winding;

$v_{\text {sh }} \quad$ phase voltage of the $h$-th stator winding;

$e_{s h} \quad$ e.m.f. induced in the $h$-th stator winding;

$l_{\sigma s}, r_{s}$ leakage inductance, resistance of the stator winding;

$l_{b}, r_{b} \quad$ rotor bar inductance, resistance;

$l_{e}, r_{e}$ rotor end-ring inductance, resistance between consecutive bars;

$p \quad$ pole-pairs;

$N_{S} \quad$ number of series conductors per slot;

$q_{s} \quad$ stator slots per pole and phase;

J load and rotor inertia;

$L \quad$ equivalent length of the machine;

$N \quad$ number of rotor bars;

$R \quad$ mean radius of the air-gap;

Im, Re imaginary and real part;

$\delta_{v} \quad$ equivalent air-gap related to the $v$-th harmonic;

$\vartheta, \omega \quad$ electric rotor position, speed;

$\bar{\phi}_{v} \quad v$-th order space vector of spatial distribution $\phi$;

$\mu_{0} \quad$ air permeability;

$K_{v} \quad$ winding factor related to the $v$-th harmonic;

L. Di Leonardo, M. Tursini and F. Parasiliti are with Department of Industrial and Information Engineering and Economics, University of L'Aquila, L'Aquila ITA (e-mail: lino.dileonardo@univaq.it, marco.tursini@univaq.it, francesco.parasiliti@univaq.it ).

M. Popescu is with Motor Design Ltd., Wrexham, UK (e-mail: mircea.popescu@motor-design.com ).

M. Carbonieri is with the Department of Electrical Engineering, University of Padova, Padova, ITA (e-mail: edlab@dii.unipd.it )

\section{INTRODUCTION}

In recent years there has been a renewed interest in the dynamic modeling of Induction Motors (IM), also due to their use in new and particularly relevant application areas, such as automotive [1][2][3] .

Lumped Parameters (LP) models are the most used method to evaluate the transient performance of electrical motor drives, [4]. Based on a set of differential non-linear equations with constant or variable parameters, they allow a dynamic analysis with small calculation times with obvious advantages. Unfortunately, the classical analysis that uses LP models, does not take into account the air-gap space harmonics.

Indeed, the space harmonics induce voltages and harmonic currents circulating in the rotor windings. The interaction between the harmonic currents generated in the rotor and the harmonic fluxes results in harmonic torques, vibrations and the noise. These are some of the reasons of the so-called stray torques and additional losses, and in some cases they are sufficient to cause the speed-torque cusps that result in subsynchronous crawling [5].

Space harmonics are mainly considered by motor designer [6] but in recent years they are becoming more familiar to power systems engineers dealing with modern drive, due to the increase of variable frequency power systems applications [7].

Different methods have been developed in literature to take into account the space harmonics in transient analysis [8][9][10].

The main characteristic of these methods is the need to set the LPs of the model considering an off-line FEM model, with the evident disadvantages of a non-analytical implementation in terms of computational load and detuning of the FEM model.

The use of co-simulation tools based on finite elements method (FEM) is recognized as the most precise way, until today, for modeling the coupled field circuits and motion of IMs, accounting for both saturation effects and space harmonics, [11]. Indeed, the modeling of the mechanical motion and field sources variation simultaneously allow coupling the instantaneous stator and rotor fields in transient behavior.

The main drawback of co-simulation is the execution time consumption due to the necessity to frequently recall the computationally heavy FEM model to guarantee an appropriate ratio between the calculation time-step and element size and to remesh the air-gap [12]. 
This paper presents a transient model suitable for the simulation of cage induction motors accounting for the actual topology of the machine, based on the space vector theory. The model adopts an analytical approach to evaluate the Fourier components of the airgap Magneto-Motive Force (MMF), called as MMF-Wave (MMFW) in the paper.

The equations account for the geometry and physical dimensions of the stator and rotor windings and the rotor position considering the field sources, represented by the currents in the stator windings and in the rotor bars. The analytical develop is presented in section II.

In section III, the MMFW approach is compared with FEM computations in order to evaluate the impact of simplifying hypotheses on the overall accuracy. The case study is a $200 \mathrm{~kW}$ induction motor designed for traction of an electric vehicle in the frame of the Horizon 2020 "Rare Earth Free Drive" project.

Finally, in section IV, the transient model implementation is presented, based on the numerical integration of the stator and rotor voltage equations calling the MMFW procedure in every calculation time-step. Comparative elements are given in terms of calculation time with respect to the transient FEM method.

\section{DYNAMIC MODEL}

The proposed IM model is developed on the assumptions of uniform and radial air-gap magnetic field and infinite iron permeability.

The machine is represented in terms of the three-phase equivalent circuits for the stator winding and polyphase circuits for the rotor one. By assuming the stator and rotor currents as state variables, the differential model is given by by the voltage balances as follows:

$$
\begin{gathered}
{\left[Z_{s}\right]_{(3 \times 3)}\left[i_{s h}\right]_{(3 \times 1)}+\left[e_{s h}\right]_{(3 \times 1)}=\left[v_{s h}\right]_{(3 \times 1)}} \\
{\left[Z_{r}\right]_{(N \times N)}\left[i_{r k}\right]_{(N x 1)}+\left[e_{r k}\right]_{(N x 1)}=0}
\end{gathered}
$$

where $Z_{S}=\left(r_{s}+l_{\sigma s} \frac{d}{d t}\right)[I]_{(3 \times 3)}$ and $Z_{r}$ is an equivalent full matrix for the rotor which accounts for the resistance and leakage inductance of the rotor bar $r_{b}$ and $l_{b}$ and respective section of the cage end-ring $r_{e}$ and $l_{e}$ (see Fig. 3 and its explanation in the following of this section).

Assuming that internal structure of the winding is symmetric only space harmonics by odd order are present. The elements of the e.m.f.s. matrices $\left[e_{s h}\right]$ and $\left[e_{r k}\right]$ according to the space vector theory can be expressed as:

$$
\begin{gathered}
e_{s h}=z \frac{d}{d t} \operatorname{Re}\left[\sum_{v=0}^{\infty} \bar{\phi}_{2 v+1} K_{2 v+1} c_{h}^{-(2 v+1)}\right] \\
e_{r k}=\frac{d}{d t} \operatorname{Re}\left[\sum_{v=0}^{\infty} \bar{\phi}_{2 v+1} \eta_{2 v+1}^{p \frac{2 \pi}{N}} e^{-j(2 v+1) \vartheta} b_{k}^{-(2 v+1)}\right]
\end{gathered}
$$

where $z=p N_{s} q_{s}, c_{h}=e^{j(h-1) \frac{2}{3} \pi}, b_{k}=e^{j(k-1) p \frac{2 \pi}{N}}, \eta_{\nu}^{p \frac{2 \pi}{N}}$ is a coefficient introduced to evaluate the flux linkage by each rotor bar (see Appendix), and $\bar{\phi}_{2 v+1}$ is the $(2 v+1)$-th order space vector of yoke resultant flux given by:

$$
\bar{\phi}_{2 v+1}=\frac{\pi L_{c, 2 v+1}}{\gamma^{2}}\left\{\bar{\sigma}_{s, 2 v+1}+\bar{\sigma}_{r, 2 v+1}\right\}
$$

with $\bar{\sigma}_{s, 2 v+1}$ and $\bar{\sigma}_{r, 2 v+1}$ the stator and rotor linear current density, respectively, and $L_{c, v}=\mu_{0} \frac{L R}{\pi \delta_{v}}$.

The mathematical model of the motor is completed by the mechanical equations:

$$
\begin{gathered}
\frac{J}{p} \frac{d \omega}{d t}=T_{e}-T_{L} \\
\frac{d \vartheta}{d t}=\omega
\end{gathered}
$$

where the electromagnetic torque $T_{e}$ is given by:

$$
T_{e}=\frac{3}{2} p z \operatorname{Im}\left[\bar{l}_{s} \sum_{v=-\infty}^{\infty}(6 v+1) \xi_{(6 v+1)} \check{\phi}_{(6 v+1)}\right]
$$

with $T_{L}$ that represents the load torque and $\bar{l}_{S}$ defined in (9)

$$
\bar{l}_{s}=\frac{2}{3} \sum_{h=1}^{3} c_{h} i_{s h}
$$

By means of the numerical integration of (1), (2), (6) and (7), it is possible to calculate the stator currents and the electromagnetic torque.

\section{A. Stator model}

The stator flux in (5) can be calculated by the classical formulas known in literature for winding distributed in regularly spaced slots (symmetric arrangement) along the airgap, assuming an infinitesimal slot-opening width i.e. impulsive distribution of the linear current density.

For the case of study, the single-phase winding is realized with three identical full-pitch winding sections connected in series. The coils are positioned inside three contiguous slots as presented in Fig. 1.

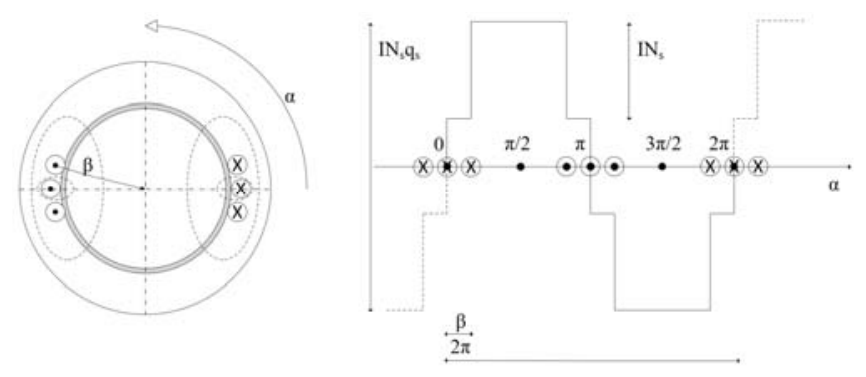

Fig. 1 Airgap MMF waveform produced by a stator phase current for distributed full-pitch windings

The following expressions are obtained for the linear current density and magnetic fields harmonic space vectors, respectively:

$$
\begin{gathered}
\bar{\sigma}_{s, v}=\frac{1}{\pi p^{2}} \sum_{h=1}^{3} z K_{v} i_{s h} c_{h}^{v} \\
\bar{H}_{s, v}=j \frac{1}{\delta_{v} \pi p^{2}} \sum_{h=1}^{3} z K_{v} i_{s h} c_{h}^{v}
\end{gathered}
$$




\section{B. Rotor model}

Due to its structure, the rotor winding of squirrel cage IM cannot be represented as the three-phase stator one if not in equivalent terms therefore losing the geometric detail.

In fact, at any time during operation, the current in each bar of the cage is different from the currents in the other bars as shown in Fig. 2. Moreover, the current flows in the end rings too.

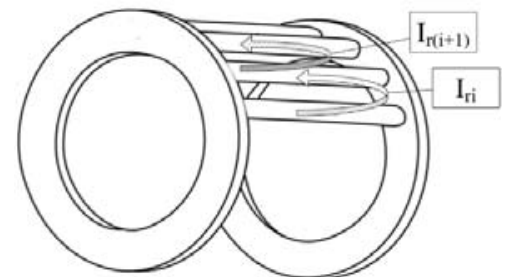

Fig. 2 Polyphase winding of the squirrel cage

The matter is addressed in literature looking at the squirrel cage as an atypical case of polyphase winding, [13].

In particular, the squirrel cage can be considered as a polyphase "ring" winding with a phase number equal to the number of bars. It follows that the current in each bar can be computed as the difference of consecutive phase currents as shown in Fig. 3 and the induced voltage for each rotor mesh (phase) can be represented as a voltage source located in series with the end-ring components.

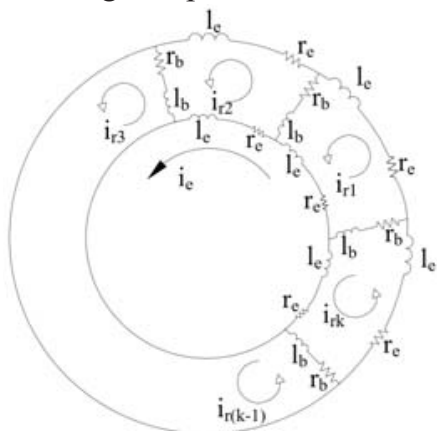

Fig. 3 Equivalent circuits of squirrel cage rotor with polyphase and end ring currents

The magnetic effects due to the proposed winding structure can be analyzed considering separately the magnetic field produced by a rotor phase current (i.e. the current flowing in opposite directions on a couple of consecutive bars).

By analogy of the three-phase stator winding and assuming the same hypothesis of infinitesimal slot-opening width, the MMF waveform due to each rotor phase can be represented as shown in Fig. 4:
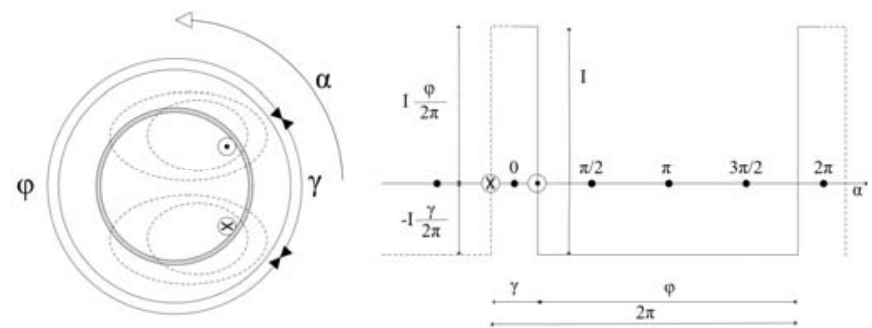

Fig. 4 Airgap MMF waveform produced by a rotor polyphase current
As the figure shows, the flux produced by the elementary winding $\gamma=2 \pi / \mathrm{N}$ wide passes through the airgap and returns spanning the angle $\varphi=2 \pi-\gamma$.

In order to evaluate the Fourier components $M M F_{v}$ of the resultant "rectangular" (with null mean value) MMF distribution in the airgap $\operatorname{mm} f(\alpha)$, the well known normalized discrete $\operatorname{sinc}(n f)$ function can be borrowed, defined as $\sin (\pi n f) / \pi n f$ with $n$ positive:

$$
\begin{aligned}
& m m f(\alpha)=\left\{\begin{array}{rl}
I \frac{\varphi}{2 \pi}, & |\alpha| \leq \frac{\gamma}{2} \\
-I \frac{\gamma}{2 \pi}, & |\alpha| \leq \frac{\varphi}{2}
\end{array} \quad-\pi<\alpha<\pi\right. \\
& M M F_{v}= \begin{cases}0, & v=0 \\
I \frac{\gamma}{\pi} \operatorname{sinc}\left(v \frac{\gamma}{2 \pi}\right), & v \neq 0\end{cases}
\end{aligned}
$$

The harmonic space vector of the linear current density, and magnetic fields, respectively becomes:

$$
\begin{gathered}
\bar{\sigma}_{r, v}=\frac{1}{\pi p^{2}} \sum_{k=1}^{N} \eta_{v}^{p \frac{2 \pi}{N}} i_{r k} b_{h}^{v} e^{j v \vartheta} \\
\bar{H}_{r, v}=j \frac{1}{\delta_{v} \pi p^{2}} \sum_{k=1}^{N} \eta_{v}^{p \frac{2 \pi}{N}} i_{r k} b_{h}^{v} e^{j v \vartheta}
\end{gathered}
$$

where $\eta_{v}^{\frac{2 \pi}{N}}$ is related to the representation of the rotor MMF waveform through the sinc function (see Appendix).

\section{CASE STUDY AND VALIDATION}

The case study refers to the IM motor developed in the frame of the Horizon 2020 project ReFreeDrive "Rare earth Free e-Drives featuring low cost manufacturing" as the traction engine of high power $200 \mathrm{~kW}$ electrical vehicles, [4].

Key points of such motor design were: 1) cost reduction through the minimization of the motor size; 2) optimized shape of the windings by hairpin technology, which permits to have a high efficiency (more than $94 \%$ considering WLTP class 3 drive cycle).

Fig. 5 shows the cross section and main geometric data of the machine, while its rated point performance are summarized in TABLE I.

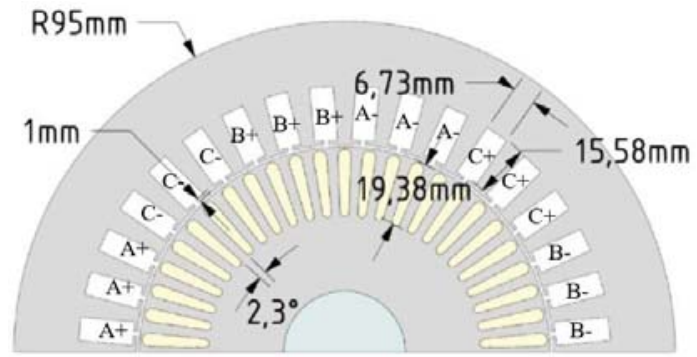

Fig. 5 Cross section and main geometric data of the IM

TABLE I. RATED POINT PERFORMANCE

\begin{tabular}{|c|c|c|c|}
\hline \multicolumn{4}{|c|}{ Rated and base values } \\
\hline Current & $589 \mathrm{~A}($ peak $)$ & Torque & $340 \mathrm{Nm}$ \\
\hline Voltage & $337 \mathrm{~V}($ peak $)$ & Speed & $6000 \mathrm{rpm}$ \\
\hline Frequency & $207 \mathrm{~Hz}$ & Slip & 0.0339 \\
\hline
\end{tabular}


In this study the FEM model of the motor has been modified respect to the design set-up in order to match a few characteristics of the proposed space harmonic model and thus allow for a safe validation of this latter, and particularly:

- infinite iron permeability is assumed;

- rotor bar opening has been introduced to avoid a nonrealistic leakage inductance (see Fig. 6).

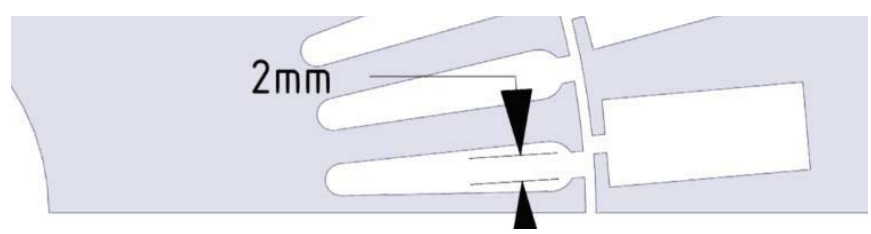

Fig. 6 - Rotor bar opening introduced to avoid a nonrealistic leakage inductance

\section{A. Validation analysis by static tests}

That portion of the MMFW algorithm referred to field generation has been analyzed by static test, i.e. simulating the impression of constant current patterns in the motor windings. The comparison with the FEM model output in same conditions allowed both to validate the overall computation and evaluate the accuracy of the method. Results are presented in term of airgap magnetic field and include both distribution waveforms and Fourier spectrums.

Different supply conditions are evaluated, by feeding currents in the only stator windings, in the only rotor cage, or in both, as described in TABLE II:

TABLE II. Static TeSt CASES

\begin{tabular}{|l|l|}
\cline { 2 - 2 } \multicolumn{1}{c|}{} & Stator winding only $\left(i_{r k}=0 \forall k\right)$ \\
\hline A. & $i_{s 1}=1 A, i_{s 2}=i_{s 3}=0 \mathrm{~A}$ \\
\hline B. & $i_{s 1}=1 A, i_{s 2}=i_{s 3}=-0,5 \mathrm{~A}$ \\
\hline & Rotor cage only $\left(i_{s h}=0 \mathrm{~A} \forall \mathrm{h}\right)$ \\
\hline C. & $i_{r k}=0 \mathrm{~A} \quad \forall k \neq 14, \quad i_{r 14}=1 \mathrm{~A}$ \\
\hline D. & $i_{r k}=\cos \left(k \frac{2 \pi}{N} p\right) A$ \\
\hline & Stator winding and rotor cage \\
\hline E. & $i_{s 1}=1 A, i_{s 2}=i_{s 3}=-0,5 A, i_{r k}=\sin \left(k \frac{2 \pi}{N} p\right) A$ \\
\hline
\end{tabular}

The values of the IM parameters used in the MMFW implementation are reported in TABLE III.

TABLE III. IM MODEL PARAMETERS

\begin{tabular}{|c|c|c|c|}
\hline \multicolumn{4}{|c|}{ Model parameter values } \\
\hline$p$ & 2 & $\delta_{v}$ & $0.8 \mathrm{~mm} \forall v$ \\
\hline$q_{s}$ & 3 & $r_{s}$ & $0,0182 \Omega$ \\
\hline$N_{S}$ & 4 & $l_{\sigma s}$ & $0,067 \mathrm{mH}$ \\
\hline$J$ & $0,0197 \mathrm{kgm}^{2}$ & $r_{b}$ & $6.85 \mathrm{e}-5 \Omega$ \\
\hline$L$ & $160 \mathrm{~mm}$ & $l_{b}$ & $5.14 \mathrm{e}-4 \mathrm{mH}$ \\
\hline$N$ & 50 & $r_{e}$ & $4.64 \mathrm{e}-7 \Omega$ \\
\hline$R$ & $59,4 \mathrm{~mm}$ & $l_{e}$ & $6.64 \mathrm{e}-5 \mathrm{mH}$ \\
\hline
\end{tabular}
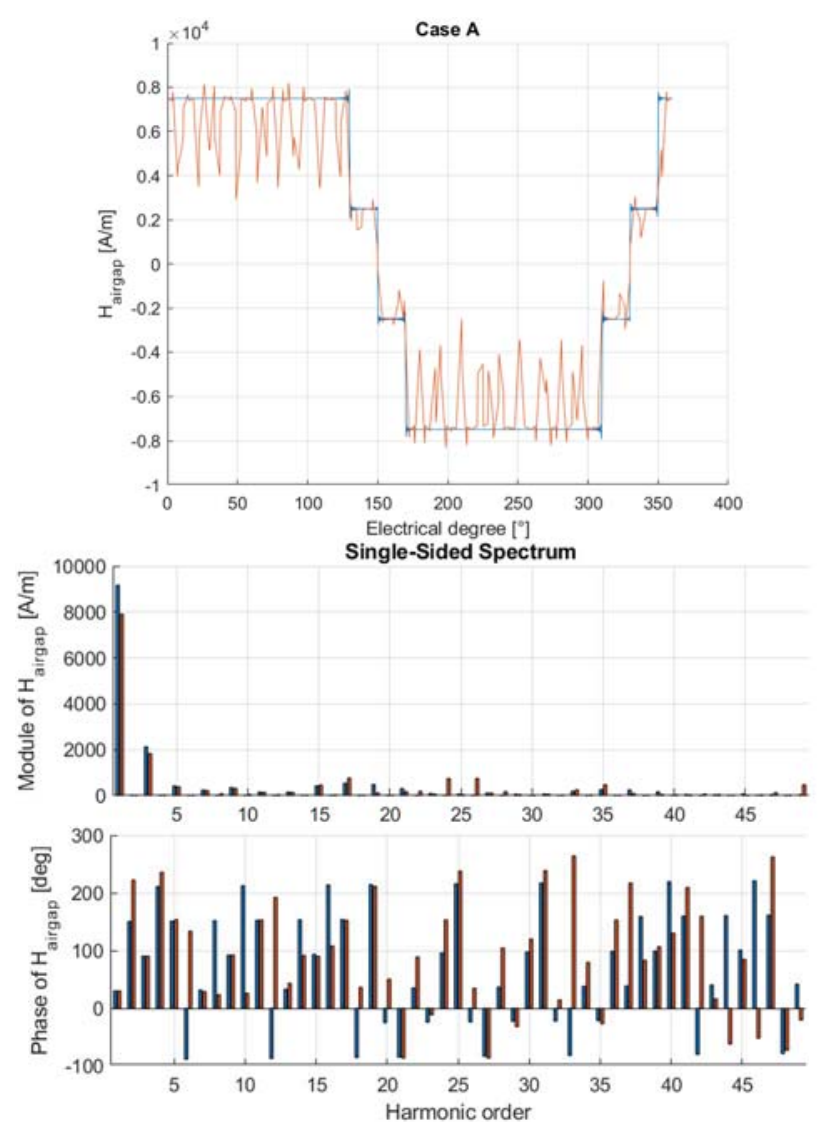

Fig. 7 Airgap magnetic field waveform and FFT in case A: MMFW (blue) and FEM model (orange)
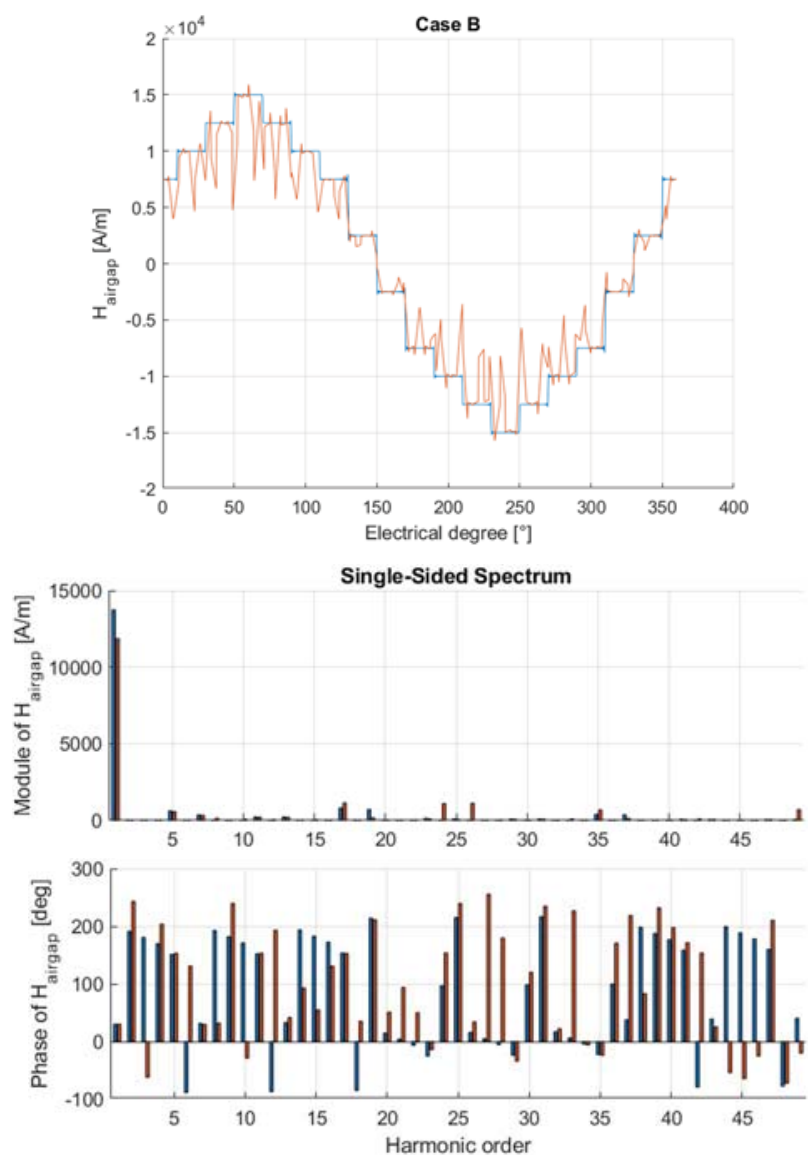

Fig. 8 Airgap magnetic field waveform and FFT in case B: MMFW (blue) and FEM model (orange) 


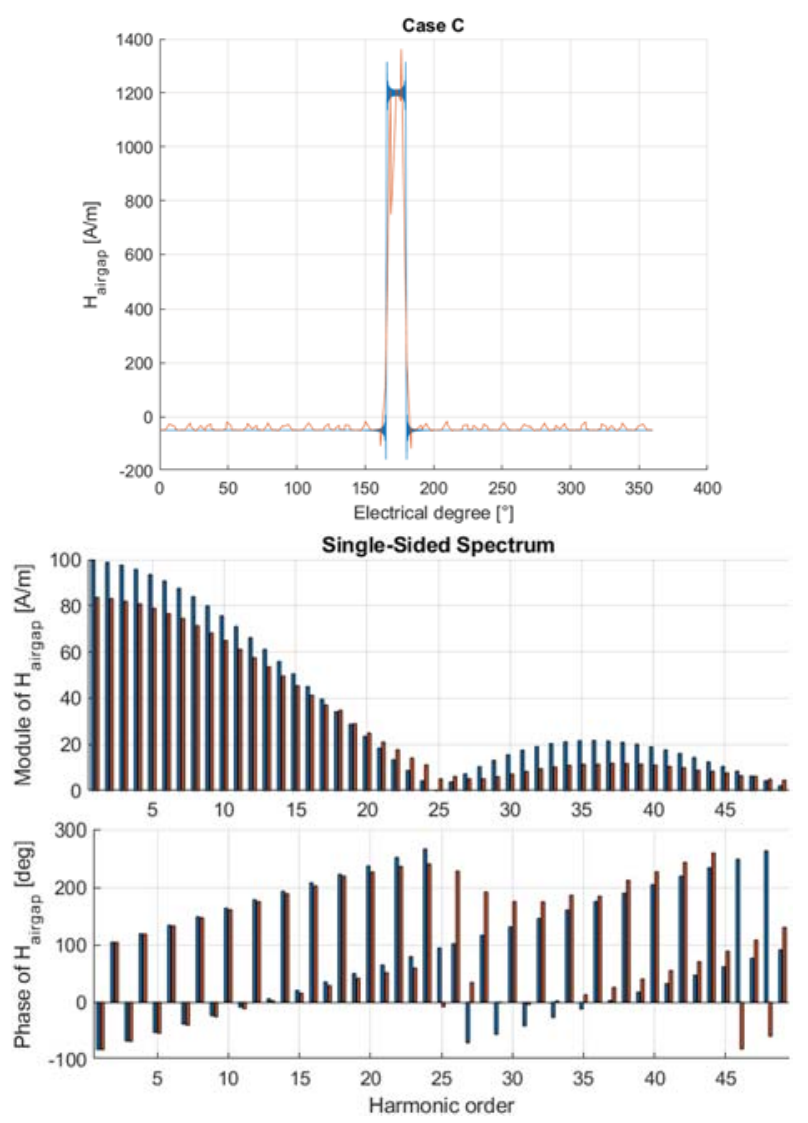

Fig. 9 Airgap magnetic field waveform and FFT in case C: MMFW (blue) and FEM model (orange)
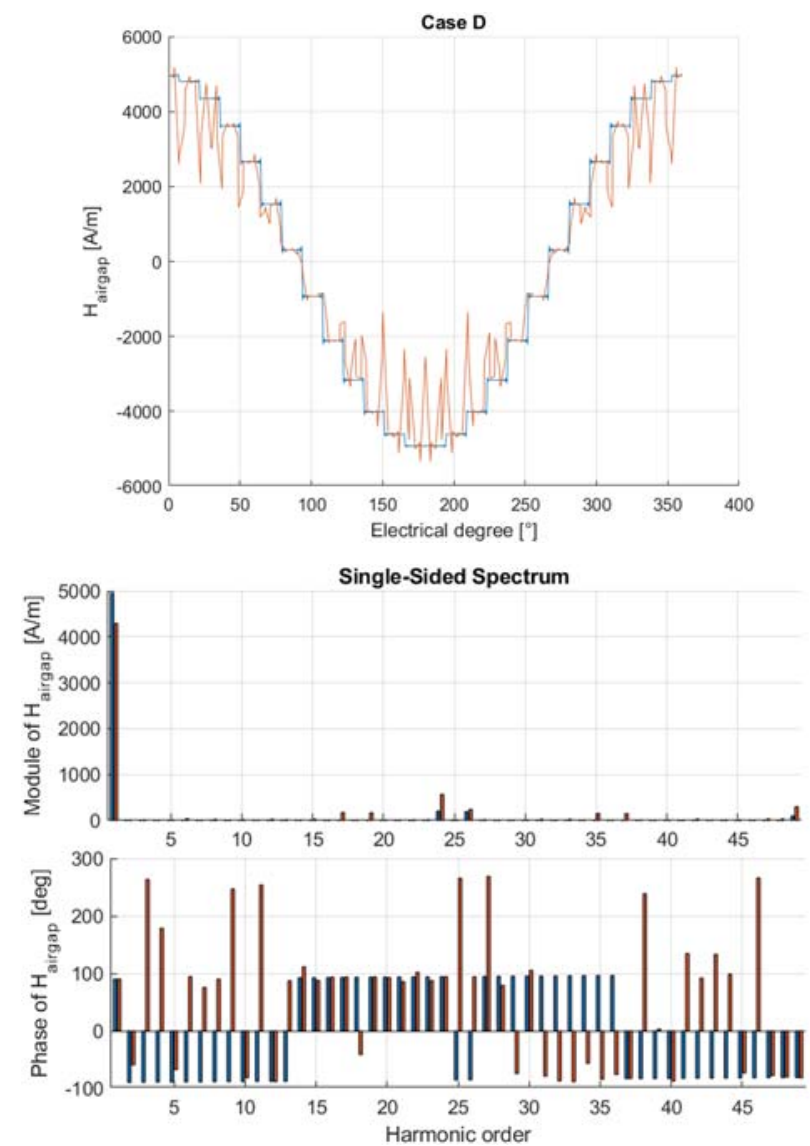

Fig. 10 Airgap magnetic field waveform and FFT in case D: MMFW (blue) and FEM model (orange)
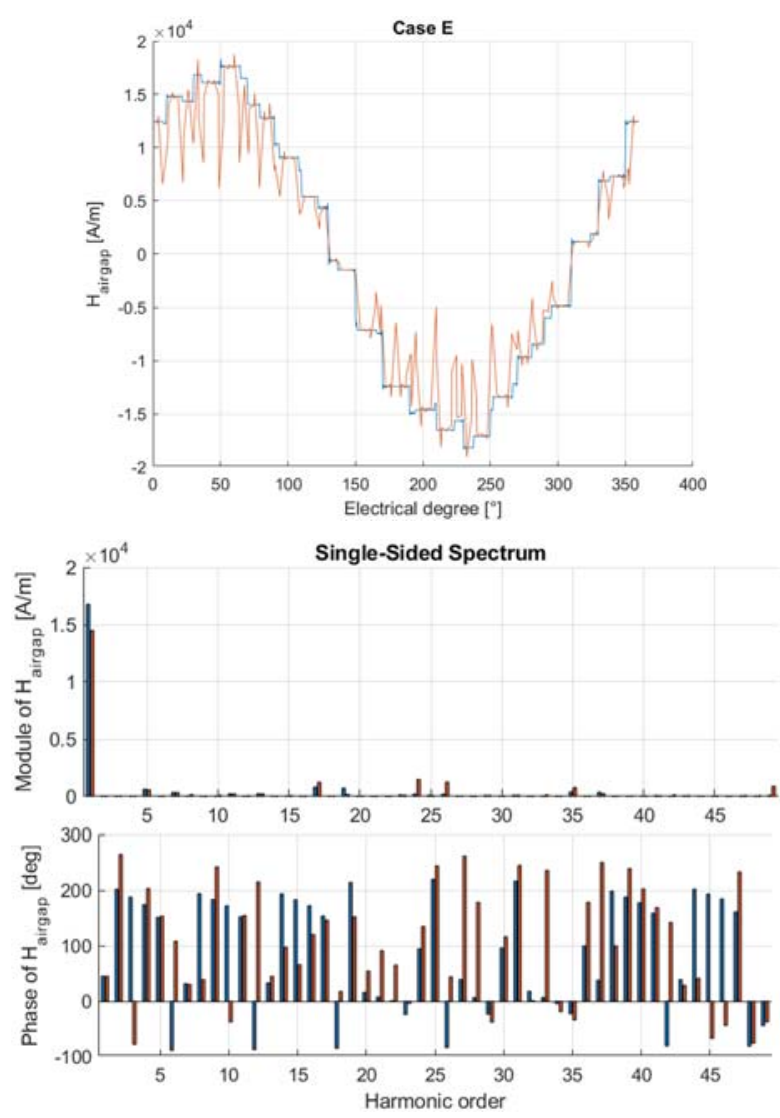

Fig. 11 Airgap magnetic field waveform and FFT in case E: MMFW (blue) and FEM model (orange)

The results show a good correspondence between the MMFW and the FEM computations, both with field sources in the stator (case A and B) and in the rotor (case C and D). The case E demonstrates the possibility to evaluate the magnetic field in the airgap by the superposition of the stator and rotor sources. The main differences between the two approaches are due to the hypothesis of assuming an infinitesimal slot-opening width. In fact, as well explained in [14], there are "field weakening peaks" in correspondence of both the stator and rotor slot-opening which are accounted by the FEM model but not by MMFW. This effect is clearly visible by the comparison of the magnetic field waveforms in the presented results and is usually managed by the Carter coefficient (and therefore defining an equivalent airgap as a function of the harmonic $\delta_{v}$ ). In this respect the mechanical airgap $(0.8 \mathrm{~mm})$ is purposely considered in the MMFW curves to allow for a reference evaluation of this effect.

\section{B. Transient model implementation and tests}

The dynamic model presented in section III, arranged for the electric equations as in (16), has been implemented in Matlab $^{\mathrm{TM}}$ and solved by using a 4-th order Runge-Kutta (RK) integration algorithm, a good compromise between calculation time and accuracy of solution [15].

$$
\begin{aligned}
& {\left[\begin{array}{c}
{\left[v_{s h}\right]_{(3 \times 1)}} \\
{[0]_{(N \times 1)}}
\end{array}\right]=\left[\begin{array}{cc}
{\left[z_{s}\right]_{(3 \times 3)}} & {[0]_{(3 \times N)}} \\
{[0]_{(N \times 3)}} & {\left[z_{r}\right]_{(N \times N)}}
\end{array}\right]\left[\begin{array}{c}
{\left[i_{s h}\right]_{(3 \times 1)}} \\
{\left[i_{r k}\right]_{(N \times 1)}}
\end{array}\right]+} \\
& +\left[L_{d}\right]_{((3+N) x(3+N))} \frac{d}{d t}\left[\begin{array}{l}
{\left[i_{s h}\right]_{(3 \times 1)}} \\
{\left[i_{r k}\right]_{(N \times 1)}}
\end{array}\right]+\omega\left[\frac{d \phi}{d \vartheta}\right]_{((3+N) \times 1)}
\end{aligned}
$$


The block-scheme of the algorithm is shown in Fig. 12. The algorithm uses the information from one time-step to compute the next one ("single-step" algorithm). In each timestep the FFMW is recalled evaluating the differential inductances matrix $L_{d}$ and the vector that links the variation of the fluxes linkage respect the rotor position $\frac{d \phi}{d \vartheta}$. In particular, $L_{d}$ and $\frac{d \phi}{d \vartheta}$ are calculated considering the incremental ratio of the linkage fluxes respect to a "small" variation respectively of the currents and the position, considering the currents and position values evaluated in the previous step. With the hypothesis of linearity of the materials, the $L_{d}$ matrix is constant.

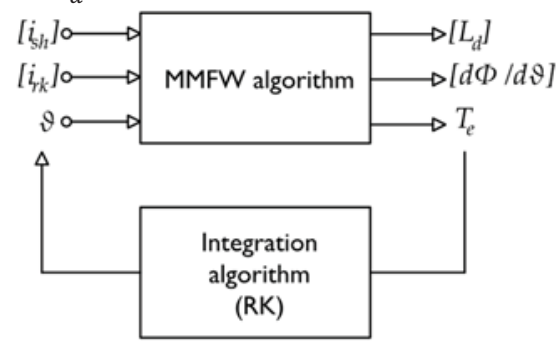

Fig. 12 Transient algorithm implementation schema

In the first test case the stator windings are excited by a voltage sudden step, with locked rotor. This test is performed to evaluate the transients of both the stator currents and the currents induced in the rotor bars avoiding disturbances due to rotor movement. Fig. 13 shows the stator currents transient and Fig. 14 the first 9 bars currents transient. Again, dynamic MMMW model responses are compared with transient FEM computations.

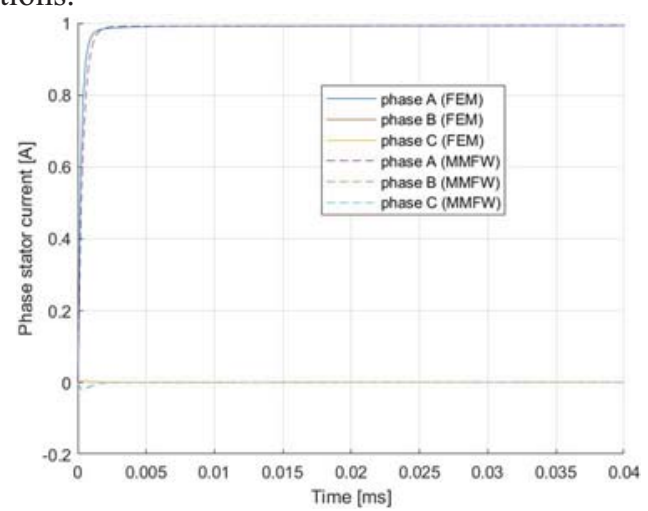

Fig. 13 Transient phase currents evaluated with MMFW (dashed line) and FEM model (continuous line)

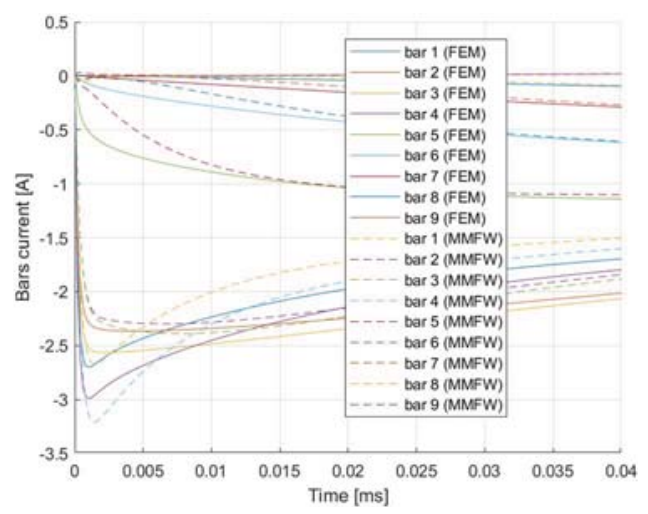

Fig. 14 Transient first 9 bars currents evaluated with MMFW MMFW (dashed line) and FEM model (continuous line)
As the figures show, the steady state values attained by the two methods are very close. This has been achieved thanks to the optimal approximation of the harmonic Carter coefficients used in MMFW following the observation pointed out in the previous section. The main differences can be observed in the transient behavior, affected mainly by variable rotor resistance due the skin effect introduced by the sudden voltage step.

The second test case refers to fixed rated speed operation (6000 rpm) with sinusoidal voltage supply and constant slip speed (337 $V_{\max }$ stator voltage, $204 \mathrm{~Hz}$ frequency, 0.0339 slip speed).

Fig. 15 represents the evaluated torque computed by the two compared methods in function of the time.

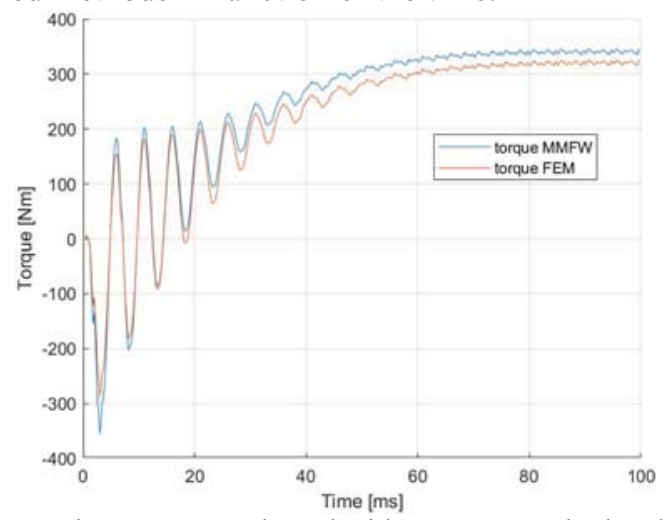

Fig. 15 Transient torque evaluated with MMFW method and FEM

In this case, the differences between the two modelling methods are more evident, both in the steady state and in transient dynamic. These can be partly ascribe to the skin effect due to the variable current in the rotor bars, nevertheless this aspect need further insight. The difference between the mean values of the torque at steady state is about $6,6 \%$ and the rms values of the current of about $3 \%$.

Differently from the previous case the effect of the movement is simulated, hence the element mesh size of the FEM model and the time step must be reduced to have a good precision, with heavy effects on calculation times. To give an indication, the simulation time for the second test case is 3 second for the MMFW method respect to the 34 min for the transient FEM, considering a classical workstation (Platinum Intel ${ }^{\circledR}$ Xeon ${ }^{\circledR} 82532,20 \mathrm{GHz}$ and $128 \mathrm{~Gb}$ of RAM).

\section{CONCLUSIONS}

In this paper, a transient mathematical model for induction motors based on space harmonics has been presented and validated by comparing finite-elements method.

The proposed analytical method makes use of simplifications to lay the theoretical foundations for the development of accurate and rapid transient analysis tools, reducing the huge computational cost of approaches based on co-simulation. The next developments concern the removal of the linearity hypothesis, considering the saturation of the materials, and adopting variable electrical parameters as, just to name a few, the bar and hairpin equivalent resistances. 


\section{APPENDIX}

Defined $I_{n}$ as the integral of the $n$-th harmonic with amplitude $A_{n}$ on a semiperiod:

$$
I_{n}=\int_{-\frac{\pi}{2}}^{+\frac{\pi}{2}} A_{n} \cos (n \alpha) d \alpha=A_{n} \frac{2}{n}
$$

the integral $I_{n}^{\gamma}$ of the same harmonic on a generic angle $\gamma$ can be express in function of $I_{n}$ as follows:

$$
I_{n}^{\gamma}=\int_{-\frac{\gamma}{2}}^{+\frac{\gamma}{2}} A_{n} \cos (n \alpha) d \alpha=A_{n} \frac{1}{n}\left(\sin \left(n \frac{\gamma}{2}\right)-\sin \left(-n \frac{\gamma}{2}\right)\right)
$$

Since sine is an odd function, $\sin (a)-\sin (-a)=2 \sin (a)$,

$$
I_{n}^{\gamma}=A_{n} \frac{2}{n} \sin \left(n \frac{\gamma}{2}\right)=I_{n} \sin \left(n \frac{\gamma}{2}\right)
$$

Thereafter, the coefficient $\eta_{n}^{\gamma}$ can be defined as the ratio between $I_{n}$ and $I_{n}^{\gamma}$ :

$$
\eta_{n}^{\gamma}=\frac{I_{n}^{\gamma}}{I_{n}}=\sin \left(n \frac{\gamma}{2}\right)
$$

\section{ACKNOWLEDGMENT}

This project has received funding from the European Union's Horizon 2020 Research and Innovation Program under the Grant Agreement No 770143.

\section{REFERENCES}

[1] M. Popescu, N. Riviere, G. Volpe, M. Villani, G. Fabri and L. Di Leonardo, "A Copper Rotor Induction Motor Solution for Electrical Vehicles Traction System," 2019 IEEE Energy Conversion Congress and Exposition (ECCE), Baltimore, MD, USA, 2019, pp. 3924-3930.

[2] N. Riviére, M. Villani and M. Popescu, "Optimisation of a High Speed Copper Rotor Induction Motor for a Traction Application," IECON 2019 - 45th Annual Conference of the IEEE Industrial Electronics Society, Lisbon, Portugal, 2019, pp. 2720-2725.

[3] M. Villani, M. Tursini, M. Popescu, G. Fabri, A. Credo and L. Di Leonardo, "Experimental Comparison Between Induction and Synchronous Reluctance Motor-Drives," 2018 XIII International Conference on Electrical Machines (ICEM), Alexandroupoli, 2018, pp. 1188-1194.

[4] L. Di Leonardo, M. Popescu, G. Fabri and M. Tursini, "Performance Evaluation of an Induction Motor Drive for Traction Application," IECON 2019 - 45th Annual Conference of the IEEE Industrial Electronics Society, Lisbon, Portugal, 2019, pp. 4360-4365.

[5] A. M. Knight and Y. Zhan, "Identification of Flux Density Harmonics and Resulting Iron Losses in Induction Machines With Nonsinusoidal Supplies," in IEEE Transactions on Magnetics, vol. 44, no. 6, pp. 1562-1565, June 2008

[6] M. Carbonieri, N. Bianchi and L. Alberti, "Induction Motor Mapping Using Rotor Field-Oriented Analysis Technique," 2019 IEEE Energy Conversion Congress and Exposition (ECCE), Baltimore, MD, USA, 2019, pp. 2321-2328.

[7] Y.Hu, Z. Zhu and K. Liu, "Current Control for Dual Three-Phase Permanent Magnet Synchronous Motors Accounting for Current Unbalance and Harmonics," in IEEE Journal of Emerging and Selected Topics in Power Electronics, vol. 2, no. 2, pp. 272-284, June 2014.

[8] D. M. Ionel and M. Popescu, "Ultrafast Finite-Element Analysis of Brushless PM Machines Based on Space-Time Transformations," in IEEE Transactions on Industry Applications, vol. 47, no. 2, pp. 744753, March-April 2011.

[9] Y. Ouazir, N. Takorabet, R. Ibtiouen and M. Benhaddadi, "TimeStepping FE Analysis of Cage Induction Motor With Air-Gap Interface Coupling Taking Into Account Phase-Belt Harmonics," in IEEE Transactions on Magnetics, vol. 45, no. 3, pp. 1384-1387, March 2009.
[10] Z. K. Papazacharopoulos, K. V. Tatis, A. G. Kladas and S. N. Manias, "Dynamic model for harmonic induction motor analysis determined by finite elements," in IEEE Transactions on Energy Conversion, vol. 19, no. 1, pp. 102-108, March 2004.

[11] L. Di Leonardo, M. Popescu, M. Tursini and M. Villani, "Finite Elements Model Co-Simulation of an Induction Motor Drive for Traction Application," IECON 2019 - 45th Annual Conference of the IEEE Industrial Electronics Society, Lisbon, Portugal, 2019, pp. 10591065 .

[12] L. Di Leonardo, F. Parasiliti, M. Tursini and M. Villani, "Transient analysis of PM synchronous motor drives by finite element model cosimulation," IECON 2013 - 39th Annual Conference of the IEEE Industrial Electronics Society, Vienna, 2013, pp. 6834-6840.

[13] H. A. Toliyat and T. A. Lipo, "Transient analysis of cage induction machines under stator, rotor bar and end ring faults," in IEEE Transactions on Energy Conversion, vol. 10, no. 2, pp. 241-247, June 1995.

[14] A. Boglietti, A. Cavagnino and M. Lazzari, "Algorithms for the computation of the induction motor equivalent circuit parameters - Part II," 2008 34th Annual Conference of IEEE Industrial Electronics, Orlando, FL, 2008, pp. 2028-2034.

[15] M. Tursini, L. Di Leonardo, C. Olivieri and E. D. Loggia, "Rapid Control Prototyping of IPM Drives by Real Time Simulation,” 2013 8th EUROSIM Congress on Modelling and Simulation, Cardiff, 2013, pp. 364-371.

\section{BIOGRAPHIES}

L. Di Leonardo received the M.S. degree in Computer and Automation Engineering at University of L'Aquila in 2010 and the Ph.D. in Electrical and Information engineering in 2014. Currently, he works as Research Fellow in the Department of Industrial and Information Engineering and Economics, University of L'Aquila. His research activities involve design, modelling and simulation of electrical machines and drive.

M. Popescu (M'98-SM'04-F'15) received the M.Eng. and Ph.D. degrees from the Politehnica University of Bucharest, Bucharest, Romania, in 1984 and 1999, respectively, and the D.Sc. degree from Helsinki University of Technology, Espoo, Finland, in 2004, all in electrical engineering. He was with the Research Institute for Electrical Machines, Helsinki University of Technology, and the SPEED Laboratory, Glasgow University, Glasgow, U.K. In 2008, he joined Motor Design, Ltd., Ellesmere, U.K., as an Engineering Manager. He has more than 25 years of experience in electrical motor design and analysis.

M. Tursini (M'99) received the M.S. degree in electrical engineering from the University of L'Aquila, in 1987. In the same year he joined the University of L'Aquila where he is currently Full Professor of power converters, electrical machines, and drives and President of the Master Didactic Area Council in Electrical Engineering. His research interests are focused on advanced control of ac drives, including vector, sensorless, and fuzzy logic control, digital motion control, DSP-based systems for real-time implementation, and modeling and simulation of electrical drives. He has authored more than 130 technical papers on these subjects.

F. Parasiliti received the M.S. degree in electrical engineering from Sapienza University of Rome, Italy, in 1981. In 1983 he joined the Department of Electrical Engineering of the University of L'Aquila, Italy, as an Assistant Professor. From 1992 to 1999 he has been an Associate Professor of Electrical Drives at the University of L'Aquila. Since 2000 he is Full Professor at the same University where he has been the Head of the Department of Industrial and Information Engineering and Economics from 2012 to 2018. From 2004 he is a member of the Steering Committee of the International Conference on Electrical Machines (ICEM). From 2010 to 2019 he has been the Vice-Chair of the ICEM Steering Committee.

Currently he is the Chair of the ICEM Administrative Committee (ex Steering Committee). His studies deal with design optimization of induction,

PM synchronous and reluctance motors, modeling and parameter observation of induction and synchronous machines and digital control of electrical drives.

M. Carbonieri received the Master degree in Electrical Engineering from the University of Padova, Padova, Italy, in 2017. He is currently Ph.D. student in the Electric Drives Laboratory, University of Padova, working on the design and analysis of electric machines. 